\title{
Protective role of adjuvant and potassium permanganate on oxidative stress response of Nile tilapia (Oreochromis niloticus) challenged with Saprolegnia ferax
}

Eman Zahran ${ }^{1 *}$ and Engy Risha ${ }^{2}$

\begin{abstract}
Saprolegniosis are one of the most important oomycetes affecting freshwater fish worldwide. It leads to huge losses in fish farms due to their massive destruction to the fish epidermis leading to sever heamodilution and death, yet little literature studied the oxidative stress response regarding the saprolegniosis. Nile tilapia fish were subcutaneously abraded and divided into four groups: control group, abraded but not challenged, infected group, challenged with Saprolegnia. ferax (S. ferax) zoospores $2 \times 10^{4}$ for one week, potassium permanganate $\left(\mathrm{KMnO}_{4}\right)$ group, challenged with $\mathrm{S}$. ferax zoospores $2 \times 10^{4}$ for one week then treated with $\mathrm{KMnO}_{4}$ and lasted for 2 weeks after, Freund's complete adjuvant (FCA) group challenged with S. ferax zoospores $2 \times 10^{4}$ for one week then treated with FCA and lasted for 2 weeks after and control positive group, challenged with S. ferax zoospores $2 \times 10^{4}$ for 3 weeks. Higher mortalities were recovered from the challenged group, which declined upon treatment compared to the continued increased rate in the control positive group. Oxidative stress indicators Nitric Oxide (NO), glutathione (GSH) and superoxide dismutase (SOD) were measured; biochemical parameters: total protein, albumin, globulin, aspartate aminotranseferase (AST), and alanine aminoranferase (ALT) were also measured. Sodium ( $\mathrm{Na}^{+}$) and potassium $\left(\mathrm{K}^{+}\right)$levels were measured as indicators of Plasma osmolality. Almost of the measured parameters showed varying reduction significant levels in treatment groups compared with the infected and the control ones. Thus, this study revealed that $\mathrm{KMnO}_{4}$ have a protective role against oxidative stress response, furthermore our data provide evidence for the role of FCA in modulating the oxidative stress response and enhancing fish immune response against infections.
\end{abstract}

Keywords: Adjuvant, Oxidative response, Potassium permanganate, Saprolegnia, Fish

\section{Background}

The fish pathogenic oomycetes, especially Saprolegnia spp; a member of the family Saprolegniaceae, causing major outbreaks in fish and fish hatcheries as well, these infections are widespread and occurred at any stage of fish life cycle (Hussein et al. 2001). Saprolegniosis characterized by a relatively superficial, cottony/woolly (floccous), white growth on the skin, or gills, or on fish eggs when in water. Initial lesions are often focal, small,

\footnotetext{
* Correspondence: eman_zahran2000@yahoo.com

'Department of Internal Medicine, Infectious and Fish Diseases, Faculty of Veterinary Medicine, Mansoura University, El-Gomheria Street, Mansoura, Egypt

Full list of author information is available at the end of the article
}

and inconspicuous, but these can rapidly enlarge because of the rapid development of the mycelium over a short period of time. Lesions may extend into dermis and the subjacent superficial musculature with time with sloughing of the epidermis (Van West 2006).

Many stressors such as adverse water temperature, poor water quality, handling, or crowding are frequently associated with outbreaks of saprolegniosis (Bailey 1984); (Copland \& Willoughby 1982); (Whisler 1997). Epithelial damage on the skin, gills, and gut, due to trauma or other pathogens, can provide a route of entry for oomycetes (Roberts 2001). Signs of disease and mortalities were culmination of two related factors: (I) rapid decreases in water temperature from $\sim 20$ to $10^{\circ} \mathrm{C}$ in $24 \mathrm{~h}$ induced 
subsequent immunosuppression; and (2) maintenance of low temperatures favoured high levels of Saprolegnia sp. , zoospores ( $\geq 5$ spores ml) (Bly et al. 1992).

Reactive oxygen species (ROS), such as superoxide anion radicals, hydrogen peroxide, and hydroxyl radicals, are continuously formed in oxygen-consuming organisms. Presence of toxic chemicals or pollutant or infection in fish environment could help in production of these ROS and so create an imbalance and it can result either in subsequent down regulation of the antioxidative response or oxidative damage outright in organisms (Valavanidis et al. 2006). Oomycetes infection in fish produce damage to the epidermis with mycelial penetration, thus fish like other vertebrates, defend their self-using the antioxidant defense system (Alvarez et al. 2005).

Treatment of water mold infection is very difficult and legally available drugs are also limited. Potassium permanganate, copper sulfate and formalin have been used for treatment of water mold infection. Furthermore, salt dips are also used to treat water molds and help to counteract the osmotic stress in the infected fish with damage skin (Treves-Brown, 2000; and Straus et al., 2009). Malachite green (MG) has consistently been the most effective oomyceticidal among numerous compounds tested widely used to treat water mold infections on fish and their eggs, however; many countries have banned the use of MG in food-fish production because of its risk to human health (Treves-Brown, 2000). Thus, many drugs have had been screened for their anti-water mold activity to try to replace MG. Potassium permanganate has been tested as a fungicide on eggs of several fish species. Effective dosages have been found to vary with the fish species tested.

Immunostimulant are agents used to enhance the nonspecific immune response (Sakai 1999). They include synthetic chemicals, drugs, and various natural products. Adjuvants are usually mixed with specific antigen preparations in order to elevate a specific immune response. However, they can also be used alone to elicit only a nonspecific response. Freund's adjuvant was one of the first immunostimulant to be used in animals and has been shown to elicit a nonspecific immune response (Olivier et al. 1985; Olivier et al. 1986b; Chen et al. 1998).

Tilapia (Oreochromis sp.) is one of the most important cultured freshwater fish worldwide, due to faster growth rate in warm waters, resistance to adverse conditions, relatively low production cost, meat quality and flavour, high protein content, and consumer preference for its phenotype (especially, its attractive colour). In Egypt, Nile tilapia (Oreochromois niloticus) is one is one of the most significant species for fish farming and for biological studies as well (Zaitseva et al. 2006).

In Egypt, fish farmers suffered from outbreaks of Saprolegniasis in their farms causing severe damage; affecting eggs hatchability and evoke higher mortalities. Most literature concerned with the pathogenicity of $S$. parasitica; we would like here to investigate the pathogenicity of a pathogenic isolate of $S$. ferax. To our knowledge there is no studies have been conducted to investigate the effect of different treatment methods against the oxidative stress response induced by Saprolegnia infection in fish. Thus, to better understand their activities underlying Saprolegnia infection, we assessed the effect of two different treatments; potassium permanganate $\left(\mathrm{KMnO}_{4}\right)$ as chemical treatment and Freund's complete adjuvant (FCA) as chemical synthetic immunostimulant on the induced mortalities and the oxidative stress response as well as biochemical parameters in Saprolegnia challenged Nile tilapia, the most important cultured fish in Egypt.

\section{Results}

\section{Pathogenicity experiment}

The result showed that the mortality reached levels of $25,27.5$ and $30 \%$ of mortality in and $\mathrm{KMnO}_{4}, \mathrm{FCA}$, and control positive group, respectively. The mortality declined to 15 and $10 \%$ by the second week in $\mathrm{KMnO}_{4}$ and FCA groups, respectively. No mortalities were recorded in the second week after treatments for $\mathrm{KMnO}_{4}$ and FCA groups. However, the number of dead fish was continued to increase in control positive group peaked up to $92.5 \%$ after 3 weeks. No mortalities occurred in the control negative group (Table 1).

The affected fish had typical signs of water mold infection, with cotton-like growths on the body and fins associated with listlessness, erratic swimming, and rising near water surfaces or resting with their abdomen on the aquarium. All dead fish showed mycelia growth on the body (Figure 1).

\section{Effect on oxidative enzymes \\ Potassium permanganate $\left(\mathrm{KMnO}_{4}\right)$ treatment group}

1) Antioxidant response:

NO level was significantly increased at week1 in the infected group compared to the control negative group. In $\mathrm{KMnO}_{4}$ it significantly increased at week 2

Table 1 Nile tilapia (Oreochromis niloticus) mortalities per week, total mortalities (TM) \% and survival \% out of $\mathbf{4 0}$ individuals /group for 3 weeks (1st W, 2nd W and 3rdW) to $\left(2 \times 10^{4}\right.$ spore/L) zoospores of S. ferax

\begin{tabular}{lccccc}
\hline Groups & \multicolumn{3}{c}{ Mortality\% } & TM\%/group & Survival \% \\
\cline { 2 - 4 } & 1st W & 2nd W & 3rd W & & \\
\hline $\mathrm{KMnO}_{\mathbf{4}}$ & 25 & 15 & 0 & 40 & 60 \\
FCA & 27.5 & 10 & 0 & 37.5 & 62.5 \\
+ve control & 30 & 42.5 & 20 & 92.5 & 7.5 \\
-ve control & 0 & 0 & 0 & 0 & 100 \\
\hline
\end{tabular}




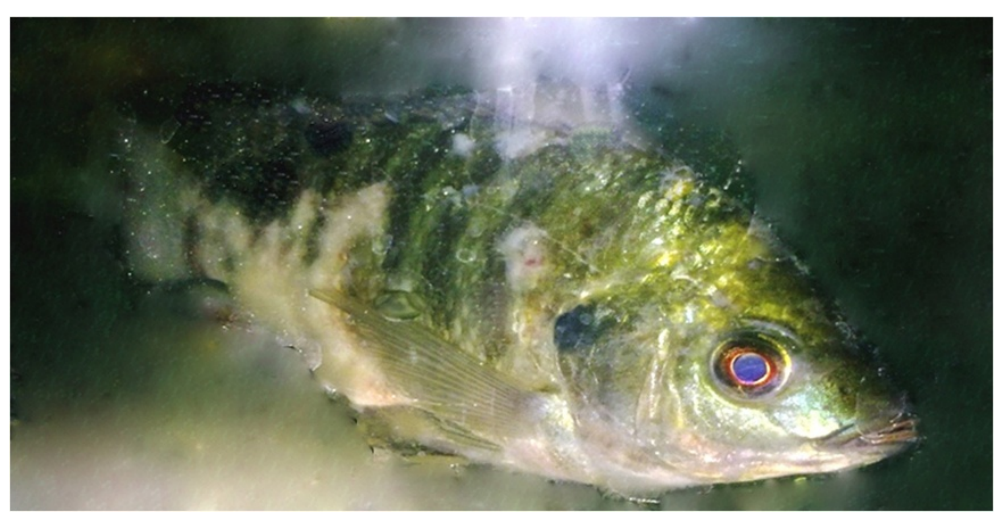

Figure 1 Nile tilapia experimentally infected with $2 \times 10^{4}$ of S. ferax, showing cotton wool like masses on the body.

and 3 compared to the control group. However, there were no significant differences in NO level between $\mathrm{KMnO}_{4}$ group and infected group

(Figure 2a).

GSH level was significantly increased at week 1 in the infected group in comparison to their control. While at week 2 and 3 , the level had a significant a threefold and two fold decreases compared to the infected one; respectively. GSH level was neither significantly different at week 2 and week 3 in $\mathrm{KMnO}_{4}$ group nor from the control group (Figure 2a).

SOD encounter a significant decrease in the infected group at week1 compared to the control where it remained at a lower level at week 2 in $\mathrm{KMnO}_{4}$ group. However, SOD had a significant rise again by week 3 after $\mathrm{KMnO}_{4}$ treatment to match within control level (Figure 2c).

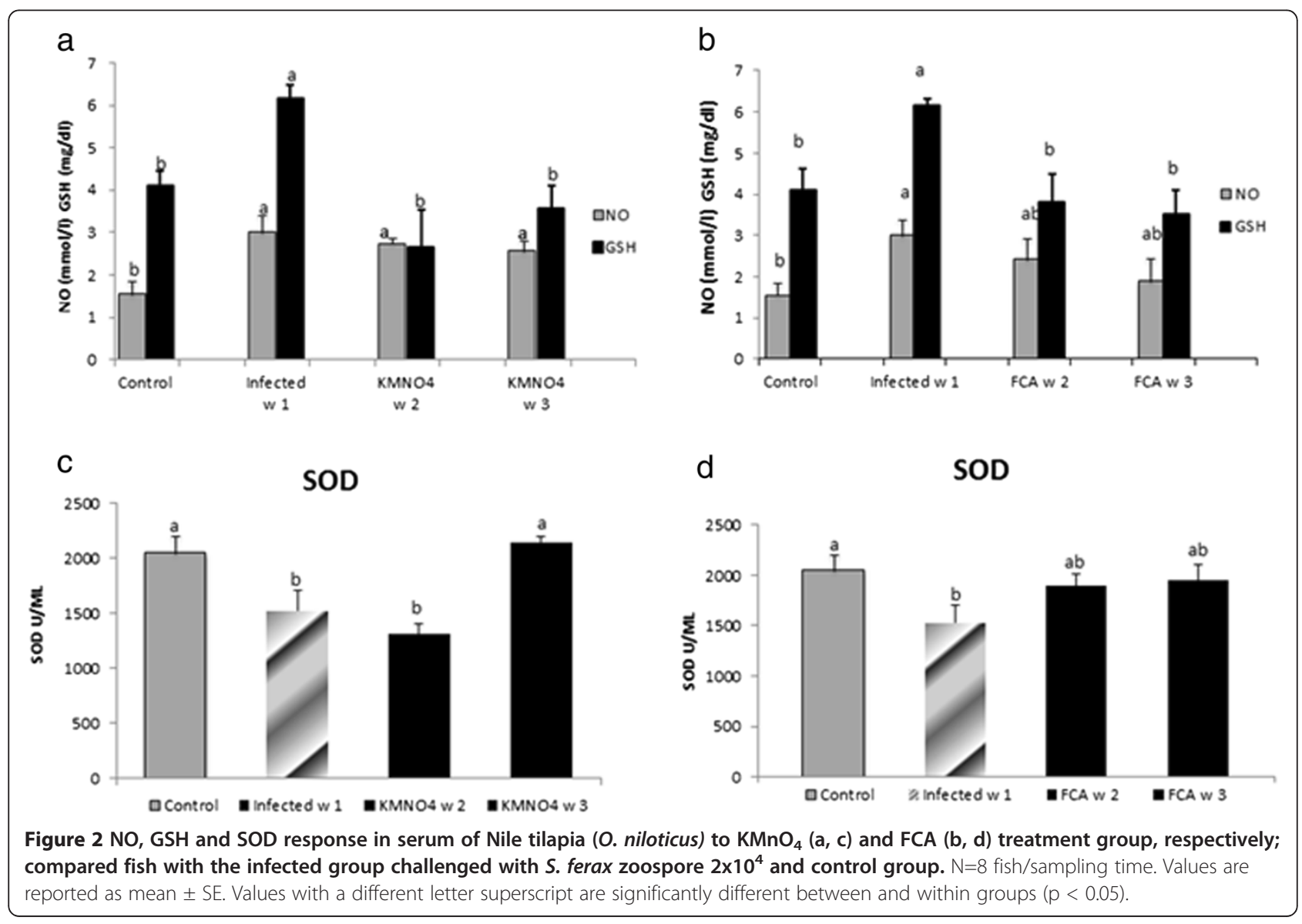


2) Biochemical analysis and plasma osmolality: ALT levels showed no significant changes at any time of experiment. However, AST had a significant rise in the infected group at week 1 which declined by week 2 and 3 in $\mathrm{KMnO}_{4}$ group to be within the control level (Figure 3a).

Results showed that albumin level had a nonsignificant nominal decreased at week 1 in the infected group compared to control group, however; in $\mathrm{KMnO}_{4}$ group, the level was significantly decreased at week 2 and 3 compared to the infected and the control group (Figure 3c).

Nile tilapia plasma $\mathrm{Na}^{+}$concentrations had a nominal increase at week 1 in the infected group as well as at week 2 and a significant increase at week 3 in $\mathrm{KMnO}_{4}$ group compared to the control group. However, there were no significant differences between both the infected group and $\mathrm{KMnO}_{4}$ group. Plasma $\mathrm{K}^{+}$concentration had another trend in which a significant increased level occurred at week 1 in the infected group and week 3 after $\mathrm{KMnO}_{4}$ group while it has a non-significant decrease by week 2 in $\mathrm{KMnO}_{4}$ group (Figures 4a, 5c).

\section{Adjuvant (FCA) treatment group}

1) Antioxidant response:

NO level was significantly increased in the infected group compared to the control one. However, there were no significant differences between the $\mathrm{NO}$ level at week 2 and 3 in the FCA group or with any other group. GSH level was the same manner like the $\mathrm{KMnO}_{4}$ group (Figure 2b). SOD encounter a significant decrease in the infected group compared to the control. The level was increased nominally by week 2 and 3 in FCA group (Figure 2d).

2) Biochemical analysis and plasma osmolality: ALT and AST levels exhibited same pattern like the $\mathrm{KMnO}_{4}$ group (Figure 3b). Albumin level had a different pattern; it has a significant decrease at week 1 in the infected group. However, it encountered a significant increase at week 2 and 3 in FCA group compared to the infected one and there were no significant between both times and the control one (Figure 3d).

Nile tilapia plasma $\mathrm{Na}^{+}$concentrations had a nominal increased in the infected group at week 1 .

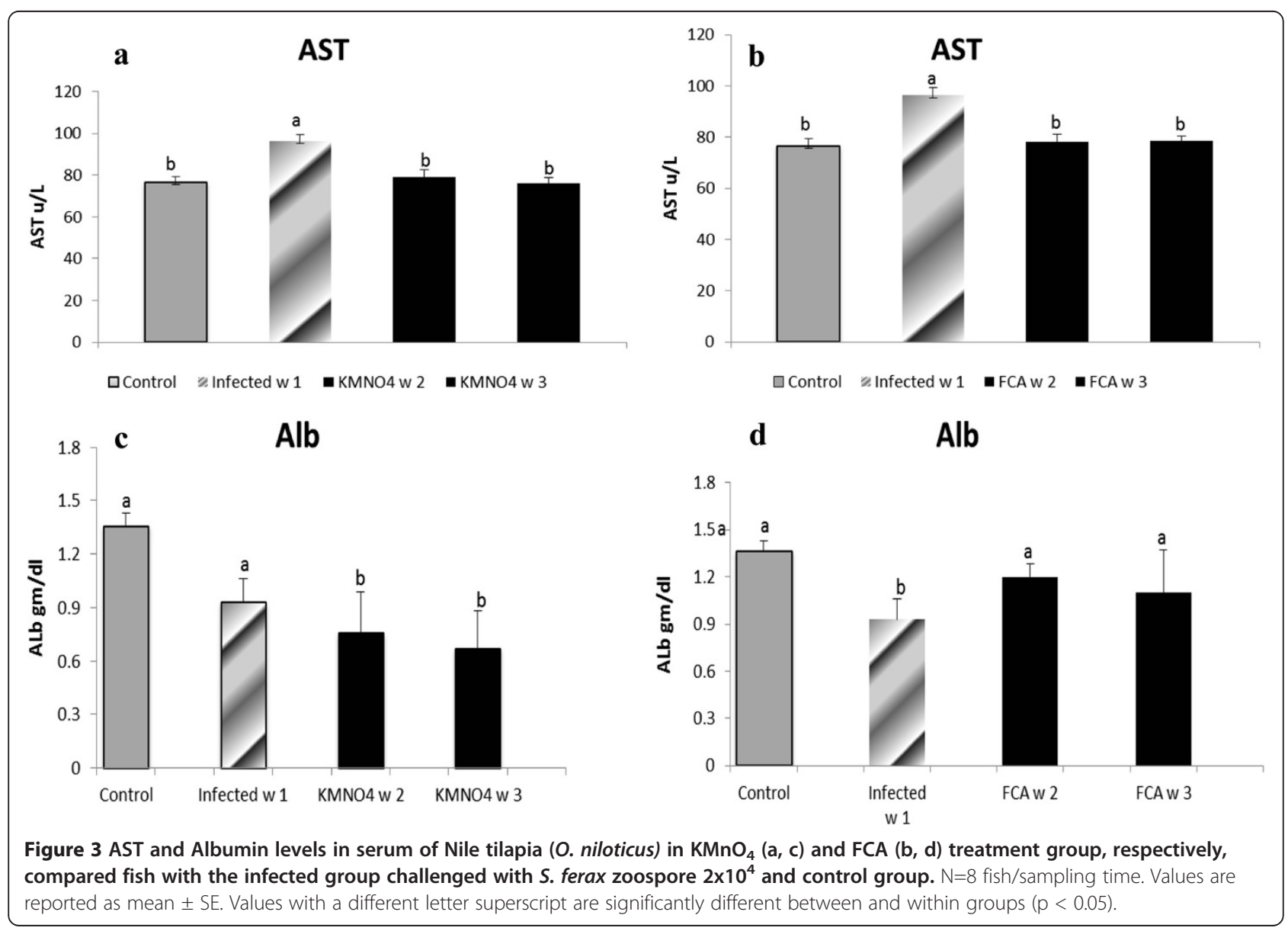



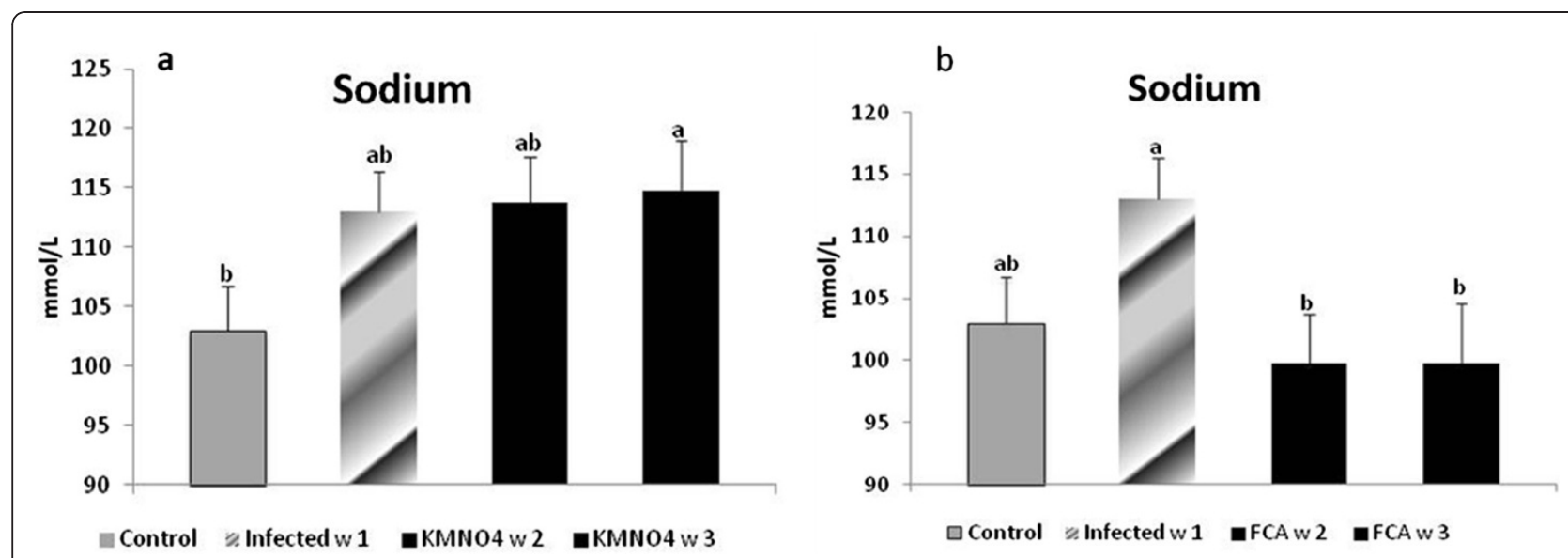

Figure 4 Sodium level in serum of Nile tilapia (O. niloticus) in $\mathrm{KMnO}_{4}(\mathrm{a})$ and $\mathrm{FCA}$ (b) treatment group, compared with the infected group challenged with $S$. ferax zoospore $2 \times 10^{4}$ and control group. $N=8$ fish/sampling time. Values are reported as mean $\pm S E$. Values with a different letter superscript are significantly different between and within groups $(p<0.05)$.

However, its level had a significant decrease again by week 2 and 3 in FCA group in comparison to both infected and control groups. Plasma $\mathrm{K}^{+}$

concentration significantly increased at week 1 in the infected group. At week 2 in FCA group the level decreased again significantly compared to the infected group; but was not significant compared to the control group (Figures 4b, 5d).

\section{Discussion}

Saprolegniosis is one of the most important oomycetes infections that can cause huge economic losses in cultured ecosystems (Van West 2006; Phillips et al. 2008). Our results clearly demonstrated the pathogenicity of S. ferax to Nile tilapia associated with higher mortalities. The present results were in agreement with (Stueland et al. 2005) who found that two of seven Saprolegnia spp. strains, tested for their pathogenicity to Atlantic salmon Salmo salar, caused $89 \%$ and $31 \%$ cumulative mortality in challenged salmonids. These strains were significantly more pathogenic than the other strains tested. Moreover, (Hussein and Hatai 2002) reported that the cumulative mortalities of the different salmonids fish groups exposed to $2 \times 10^{5}$ spore/L concentrations of S. salmonis NJM 9851 were $90 \%$ for brown trout, $93.3 \%$ for sockeye salmon and $100 \%$ for rainbow trout, masu salmon, and Japanese char, however; all salmonid species exposed to $2 \times 10^{5}$ spore/L concentrations of S. parasitica NJM 9868 had a cumulative mortalities of $100 \%$. Saprolegnia lesions were in form of cottony like masses on different sites on fish body mainly in the dorsal region and on the dorsal and adipose fins (Yanong 2003) which in same event with our results lesion appeared mostly in all sites which are exposed to scarification during descaling process. The death mainly occurred due to the osmotic failure caused by the damaged epidermis (Bruno and Poppe 1996).
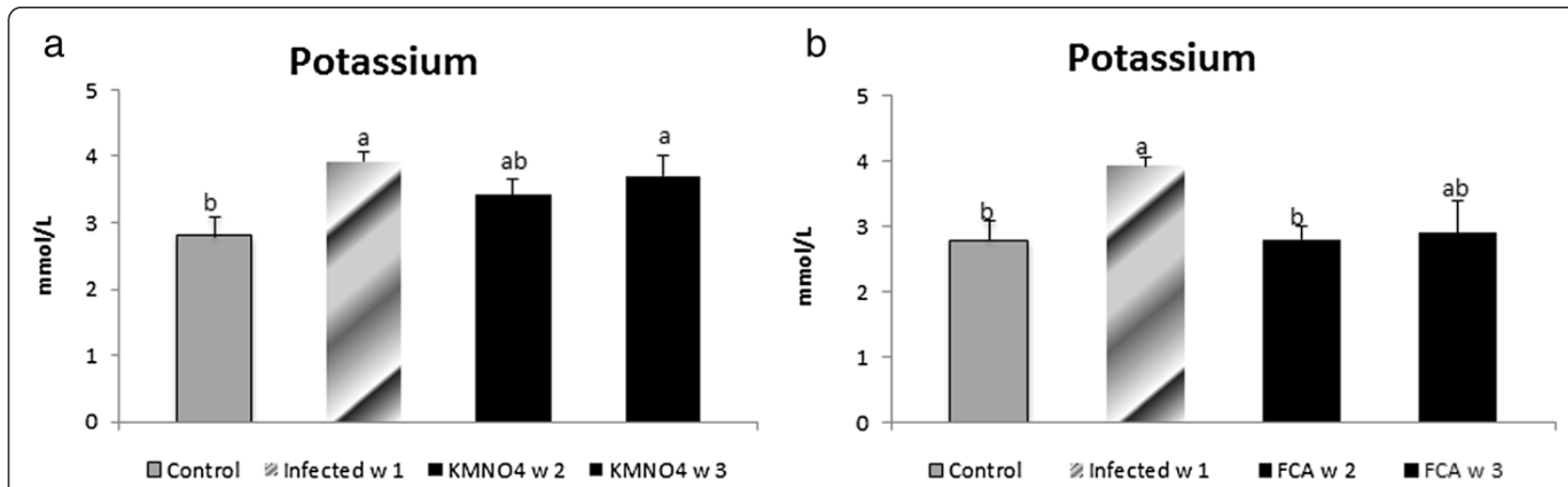

Figure 5 Potassium level in serum of Nile tilapia (O. niloticus) in $\mathrm{KMnO}_{4}$ (c) and FCA (d) treatment group, compared fish with the infected group challenged with s. ferax zoospore $\mathbf{2} \times \mathbf{1 0} \mathbf{4}^{4}$, and control group. $\mathrm{N}=8$ fish/sampling time. Values are reported as mean $\pm \mathrm{SE}$. Values with a different letter superscript are significantly different between and within groups $(p<0.05)$. 
Our results showed that Potassium permanganate as a chemical treatment lowering the mortality to $15 \%$ in the 2nd week and 0 in the 3 rd week; compared to 42.5 and $20 \%$ of mortality by 2 nd and 3rd week in the control positive group, respectively. The most effective treatment for controlling saprolegniosis is the malachite green; however, since it has several drawbacks (Schreier et al. 1996) it's not permitted for use in fish-farming in most countries. Thus, the need to search for alternative compounds as effective as malachite green is imperative.

Potassium permanganate is used for ectoparasites, bacteria, fungal disinfections on the skin and gill of fishes, it act as an oxidant through decreasing BOD of water by oxidize the organic matter and the amount of oxygen will be increase by using potassium permanganate (Noga 2010). (Marking et al. 1994) examined two In the same event, (Rasowo et al. 2007) investigated the effect of formaldehyde, sodium chloride, potassium permanganate and hydrogen peroxide treatment for saprolegniosis in catfish (C. gariepinus) eggs and found that the best hatchability performance was when eggs treated with $2 \mathrm{ppm}$ potassium permanganate for $30 \mathrm{~min}$ (96.7\%). (Darwish et al. 2009) evaluate the efficacy of $\mathrm{KMnO}_{4}$ at a dose of 2.0 $\mathrm{mg} / \mathrm{L}$ above the potassium permanganate demand for $2 \mathrm{~h}$ duration against Columnaris infection in channel catfish using different route of administration and found that using $\mathrm{KMnO}_{4}$ simultaneously with challenge give 99\% survival while using $\mathrm{KMnO}_{4}$ postchallenge enhanced survival (85\%) than positive control (78\%); which conclude overall efficacy of $\mathrm{KMnO}_{4}$ as a treatment against skin infection. (Marking et al. 1994) reported that potassium permanganate at two concentrations 50 and $100 \mathrm{mg} / \mathrm{l} \mathrm{de}-$ creased fungal infection of rainbow trout eggs but rate of hatching didn't increase. Our results were supported by (Thomas-Jinu and Goodwin 2004) who found that $\mathrm{KMnO}_{4}$ reduced columnaris mortality from $100 \%$ to $69 \%$.

Adjuvant treatment as immunostimulant improved the mortality rates from $27.5 \%$ to $10 \%$ from the first to the second week compared to the control positive which encountered $30 \%$ and $42.5 \%$ of mortality in week 1and 2 . Furthermore, no mortalities were recorded in the 3rd week in FCA group. In addition, FCA treatment showed to some extent a better rate for fish survival compared to $\mathrm{KMnO}_{4}$ treatment in the second week after challenge. To our knowledge, there are no studies for using FCA alone as immunostimulant to enhance fish immunity infected with saprolegniosis or investigate its effect regarding the antioxidant response in fish. However, Many coworkers have shown that the adjuvant has a great effect on innate immune response; For example, injection of FCA induces nonspecific protection against several bacterial pathogens and ciliate pathogen of fish (Olivier et al. 1985; Kajita et al. 1992). (Olivier et al. 1985) showed increased resistance of coho salmon (Oncorhynchus kisutch) to
Aeromonas salmonicida after injection of the same preparation of FCA that we used in our studies (i.e., with killed Mycobacterium butyricum). Thus, this augmentation of the immunity reflected on the host response to evade the infection. In the same context, (Harikrishnan et al. 2009) found that a prior administration of a triherbal mixure of medicinal plant compounds, azadirachtin (Az), camphor $(\mathrm{Ca})$ and curcumin $(\mathrm{Cu})$, affected mortality rate positively upon changing with virulent starin of Aphanomyce invadans. On the contrary, (Kunttu et al. 2009) evaluate the efficacy of two immunostimulants, yeast b-glucan and b-hydroxy-b-methylbutyrate (HMB) to treat the Fingerling rainbow trout experimentally infected with Flavobacterium columnaris, and found that given orally both stimulants enhanced the levels of immune function parameters, but did not improve survival in challenge at any concentration of the stimulants used. Intra peritoneal injection of $\beta$ glucan increased parameter values several fold, but no beneficial effect of injected glucan on survival was observed. (Zahran et al. 2012) have found that adjuvant parenteral administration in channel catfish could elect a nonspecific defence by expressing antimicrobial polypeptides histone like protein-1 (HLP-1) at a distant site (skin) HLP-1 known with its potent bactericidal, parasiticidal and funigicidal activity (Robinette et al. 1998).

Saprolegnia infection resulted from many stress factors that fish are exposed, these factors lowering its resistance and enhance fish susceptibility to infection, Saprolegnia act through secreting proteolytic like enzymes that alter integument integrity and facilitate penetration (Peduzzi and Bizzozero 1977).

Antioxidant activity in our study showed different patterns between both treatments to some extent; but as general both treatment had general same effects regarding the antioxidant response. $\mathrm{NO}$ is an important regulating signaling molecule, it produced endogenously from L-arginine and molecular oxygen by the enzyme nitric oxide synthase (Bogdan 2001). NO mediate its biological activity by binding with different targets such as, heme groups, cysteine residues, and iron and zinc clusters, thus a certain regulation of NO production is required to mediate its biological effect. When NO level is too high that may indicate presence of toxicity, stressful conditions, infectious agent that all participate in occurrence of the disease (Farrell et al. 1992; Ignarro 2000; Vladutiu 1995). In the present result, NO level significantly increased in the infected group, while with both treatments they significantly decreased to within the normal value. A similar response was observed in rainbow trout inoculated with a virulent strain of Renibacterium salmoninarum compared with avirulent strains (Camposperez et al. 2000), In the same trend (Acosta et al. 2004) found enhanced response in serum concentrations of stable nitric oxide (NO) metabolites in small weight 
gilthead sea bream (Sparus aurata) (30-75 g body weight) lasting from $6 \mathrm{~h}$ to six days post-infection with a peak at $24 \mathrm{~h}$; when inoculated of with a sublethal dose of different Photobacterium damselae subsp. piscicida (Pdp) strains (DI-21 and 94/99), however; no such response was detected in larger fish (150-600 g).

GSH is an important antioxidant and the amount of GSH present could reflect the antioxidant potential of an organelle (Liu et al. 2008). GSH activities were significantly higher during the challenge in the infected group. This could be attributed to the induction of Reactive oxygen species (ROS), and so more antioxidant enzymes are released to compensate the damage produced by infection (Di Giulio et al. 1989; Storey 1996). (Wilhelm Filho et al. 2002) found that gill tissues are one of the main contributors of ROS generation in fish. This explanation is supported also by other studies by (Thomas and Wofford 1984; Gallagher et al. 1992; Thomas and Juedes 1992) where they demonstrated higher level of GSH following exposing fish to stressor. (Oliveira et al. 2008) showed a higher adaptive competence expressed as antioxidant defenses activation, namely GSH and glutathione peroxidase (GPX) in Liver against different concentration of Phenanthrene. However, SOD level was significantly reduced upon challenge and that could be due to disruption of erythrocyte membranes by ROS caused hemorrhage and loss of antioxidant enzymes in human immunodeficiency virus (HIV-infected humans); and the typical symptom in grass carp hemorrhage virus (GCHV) infected grass carp is erythrocyte hemolysis and bleeding in the muscle may relate to the significantly decreased SOD and catalase (CAT) activities (Zhang et al. 2003) when the grass carp were infected with GCHV. Interestingly, a significant decrease in SOD was also observed in white spot syndrome virus (WSSV) infected Penaeus monodon (Chang et al. 2003). Our results in accordance with (Kim et al. 2009) who examined the effect of $\beta$-glucan, an immunostimulatory agent, on the superoxide dismutase (SOD) and catalase (CAT) activities of erythrocytes and Mx gene expression in grass carp challenged with grass carp hemorrhage virus $(\mathrm{GCHV})$ and found that the SOD and CAT activities significantly decreased when the fish were challenged with GCHV, but it was higher in the group pre-treated with $\beta$-glucan than in infected. Similar results were obtained in Wister rats when injected mangiferin $\mathrm{I} / \mathrm{P}$ at different dose to overcome cyclophosphamide toxicity; showing that Cyclophosphamide significantly lowered the superoxide dismutase and catalase (CAT) activities in lymphocytes, polymorphonuclear cells (PMN) and macrophages, while the administration of mangiferin significantly protected the activities of SOD and CAT, demonstrating the antioxidant mechanism to exist in its immunoprotective role.
Thus, it's evident that the $\mathrm{KMnO}_{4}$ and adjuvant a promising tools in a protecting against immunological tissue injury may be through the regulation of antioxidant enzyme activities, thus potentiating the cellular antioxidant capacity. Moreover, it emphasize on the role of adjuvant as an immunoprotective role mediated through the inhibition of reactive intermediate-induced oxidative stress in lymphocytes, neutrophils and macrophages. Adjuvant affect macrophage activity and phagocytosis (Olivier et al. 1986a) and thus the respiratory burst activity due to an increase in the antioxidant oxidation level in phagocytes which is an important indicator of innate immune response (Miyazaki 1998).

Biochemical analysis, revealed changes in level of Albumin, AST but no changes have been found in total protein, globulin or ALT. AST level was markedly increased in the infected group compared to $\mathrm{KMnO}_{4}$ and FCA groups, while ALT didn't change. Others studies were in support to our results, they found that increased activity of AST, CK, and $\mathrm{LDH}$ are related to venipuncture, which is done through the musculature of the caudal peduncle. While, Sorbitol dehydrogenase and ALT appear to be present in low concentration in skeletal muscle and may be better indicators of hepatocellular damage and this indicate that there were no substantial damage to internal organ as the liver (Tripathi et al. 2003). Also, Biochemical changes in fish included significant hyperglycemia, hyponatremia, and hypochloridemia were evident in koi (Cyprinus carpio) experimentally infected with Flavobacterium columnare infection (Tripathi et al. 2005).

Albumin level exhibited a moderate decrease in the infected group compred to the control one, while it showed significant reduction by week 2 and 3 in both $\mathrm{KMnO}_{4}$ group, but in FCA the albumin level matched within the control one. This may happen as a result of epidermal damage due to Saprolegnia also, through skin ulcers present on skin surface, these can represent a portal of loss of plasma protein or that excess of water diffused to the fish body through these sites resulting in slight heamodilution (Tripathi et al. 2005). Our results were in accordance with (Ruane et al. 2002) who observed reduction in plasma protein levels in common carp after confinement and in red sea bream Pagrus major following acute handling stress (Biswas et al. 2006). In salmonids, a reduction in serum protein concentration has been observed when the fish were infected or stressed (Melingen et al. 1995; Møyner et al. 1993). These differences are possibly species-specific effects of environmental conditions on serum/plasma protein and globulin concentrations in fish.

Plasma ion concentration in the present study showed variations in their levels; $\mathrm{Na}^{+}$and $\mathrm{K}^{+}$was increased in the infected group and decreased to some extent in the other groups. This is also can be explained in the same context which account for damaged epidermis and loss 
of the integument integrity and so increase in the permeability with loss of this ions or being diffused from water into fish body. Changes in biochemical parameters in hybrid tambacu fish naturally parasitized by Dolops carvalhoi (Crustacea, Branchiura), a fish louse were in form of increases in $\mathrm{MCHC}$, plasma glucose levels, serum protein, sodium and chloride levels, number of monocytes and PAS-positive granular leukocytes (PAS-GL), when compared with values in control fish (Tavares-Dias et al. 2007). Freshwater fish body is hypertonic to the surrounding environment and so upon infection with Saprolegnia and subsequent skin damage this could results in influx of the water into fish body, potentially resulting in osmoregulatory failure and disruption in the electrolytes homeostasis (Tripathi et al. 2005).

\section{Conclusion}

In conclusion, $\mathrm{KMnO}_{4}$ has proven a beneficial effect against saprolegniosis and show a protective role against oxidative damage in saprolegniosis-infected Nile tilapia while parenteral administration of adjuvant showed better fish survival rate in Saprolegnia infected Nile tilapia due to induction of innate immune response and enhancement of fish resistance against infection. Also, it showed the ability to offer a marked protective effect against oomycetes infection in farmed fish stocks

\section{Methods}

\section{Chemical agents}

\section{Potassium permanganate $\left(\mathrm{KMnO}_{4}\right)$}

Potassium permanganate $\left(\mathrm{KMnO}_{4}\right)$; Nasr. Co., Cairo, Egypt. A stock solution of $\mathrm{KMnO}_{4}$ was prepared by dissolving $1 \mathrm{~g}$ of $\mathrm{KMnO}_{4}$ in $1 \mathrm{~L}$ of reagent grade water. $\mathrm{KMnO}_{4}$ dosed at $2.5 \mathrm{ppm}(\mathrm{mg} / \mathrm{l})$, calculated according to potassium permanganate demand average of the experimental tanks $0.5 \mathrm{mg} / \mathrm{l}+2 \mathrm{mg} / \mathrm{l}$ according to (Plumb and Hanson 2010).

\section{Freund's complete adjuvant (FCA)}

Freund's complete adjuvant (Difco \#263810), consisting of $5 \mathrm{mg}$ of killed, dessicated Mycobacterium butyricum in $10 \mathrm{ml}$ of adjuvant $(8.5 \mathrm{ml}$ paraffin oil and $1.5 \mathrm{ml}$ of manniden monooleate) was prepared immediately before use.

\section{Fungal strain}

One isolate of Saprolegnia used in challenge experiment; Saprolegnia ferax isolate. It was isolated from skin lesions of Nile tilapia suffered saprolegniosis from different fish farms in Egypt. Isolates were identified according to their morphological and sexual character and sequenced (unpublished data). Fungal isolates were cultured on glucose yeast extract (GY) agar at $19^{\circ} \mathrm{C}$. Agar with mycelia was then aseptically cut into $1 \times 1 \mathrm{~cm}^{2}$ squares and placed into a Petri dish with $30 \mathrm{~mL}$ GY broth. After 2 days, the agar remnants were removed, and the growing mycelia were cut and washed repeatedly in sterilized tap water (TW) and then transferred into $20 \mathrm{~mL}$ fresh sterilized TW and kept for $18-24 \mathrm{~h}$ at $19^{\circ} \mathrm{C}$ (Kitancharoen and Hatai 1996). After the zoospores of the tested Saprolegnia strains were harvested; they were counted with the zoospore suspension was counted using a haemocytometer (Bürker Türk) and then added to experimental tanks at a concentration of $2 \times 10^{4}$ zoospore/l.

\section{Pathogenicity experiment}

A total of one hundred and sixty Nile tilapia (O. niloticus) weighed $70 \mathrm{~g}$ were placed to eight $60-1$ aquarium tanks with freshwater at $15^{\circ} \mathrm{C}$. Fish were fed on commercial diet ad libitum and maintained under $12 \mathrm{~h}$ light/ $12 \mathrm{~h}$ dark photoperiod. Water quality during all experiments was: dissolved oxygen $6.8-7.5 \mathrm{mg} / \mathrm{l}$, temperature $15^{\circ} \mathrm{C}, \mathrm{pH}$ 6.65-6.87, unionized ammonia $<0.001 \mathrm{mg} / \mathrm{l}$ and nitrite $<0.10 \mathrm{mg} / \mathrm{l}$. Fish were acclimated for 2 weeks. Fish experimental protocol and handling was performed with regard to the ethical committee of veterinary medicine faculty and local Mansoura university rules. The fish were placed 20 fish /aquarium in duplicate aquaria per each group (40 fish/group). The experimental groups were: control negative group without zoospores exposure; infected group exposed to $2 \times 10^{4}$ zoospores of $S$. ferax per liter of water (spore/L) and $\mathrm{KMnO}_{4}$ group is the infected group treated after one week with $2.5 \mathrm{ppm}$ of $\mathrm{KMnO}_{4}$; by adding 150 $\mathrm{mL}$ of the stock solution to each treated tank, FCA group is the infected group treated after one week with intraperitoneal injection of $0.1 \mathrm{ml}$ of FCA and both groups lasted for 2 weeks after, and control positive group exposed to $2 \times 10^{4}$ spore/L for the 3 weeks experimental period. Fish in all groups were descaled on different regions on the body using sharp scalpel then, $2 \times 10^{4}$ spore/L were added to all groups except the control negative one. All aquaria were covered to minimize contamination. Water changed once a week during the treatment period with replacing the concentration of the $\mathrm{KMnO}_{4}$ to be at the same exposure level for group 2 . The aquaria were checked daily after the challenge for two weeks, and dead and moribund fish were removed for examination. Skin scrapings, gill and fin biopsies of removed fish were examined. S. ferax infection was confirmed via identification of broad aseptate hyphae, sporangia and encysted zoospores with light microscopy.

\section{Fungal diagnosis}

The diagnosis of fungal infection was based on the appearance of cottony mycelial growth on the surface of the fish. Saprolegnia infection was identified by their morphological characters on Nile tilapia by direct microscopic examination of lesion and mycological culture on glucose yeast extract (GY) agar at $19^{\circ} \mathrm{C}$. Identification was based on the classical morphological criteria of 
Seymour (1970) and Willoughby $(1978,1985)$. The numbers of fish mortalities, moribund and surviving fishes were recorded. The dead fish and controls were also collected and subjected to analysis.

\section{Oxidative enzymes and biochemical analysis}

Four fish from each group (8 fish/group) were randomly selected at week 1, 2 and 3. Blood samples were collected from the caudal vein, left to coagulate, then centrifuged for $5 \mathrm{~min}$ at $3000 \mathrm{r} / \mathrm{m}$ for serum separation to be used for serum nitric oxide (NO), superoxide dismutase (SOD) and glutathione (GSH) measurement, moreover for some biochemical parameters measurement.

1. Oxidative enzymes (Nitric oxide, SOD and GSH): The serum NO, SOD and GSH were assayed spectrophotometrically (5010, Photometer, BM Co. Germany) using commercial test kits(Bio-Chain, Inc., USA).

2. Serum biochemical analysis:

Serum aspartate aminotranseferase (AST) and alanine aminoranferase (ALT) were estimated using commercial kits (Randox UK), also total protein, albumin and serum sodium $\left(\mathrm{Na}^{+}\right)$, potassium $\left(\mathrm{K}^{+}\right)$ levels were measured sepectrophotometrically using test kits (stanbio.), biodiagnostic respectively.

\section{Statistical analysis}

Data were expressed as means standard errors. Statistical analysis was performed using the software SPSS 19 (SPSS Inc, Chicago, Illinois). All data were subjected to analyses other than mortality data, which was treated as frequency data. For all tests, the effect of experimental variables (aquarium replicate, sampling day) was tested by analysis of variance One-way ANOVA and Duncan's multiple comparisons of the means to compare data obtained. Differences between treatments were considered significant when $\mathrm{P}<0.05$.

\section{Abbreviations}

S. ferax: Saprolegnia. ferax; $\mathrm{KMnO}_{4}$ : Potassium permanganate; FCA: Freund's complete adjuvant; NO: Nitric oxide; GSH: Glutathione; SOD: Superoxide dismutase; AST: Aspartate aminotranseferase; ALT: Alanine aminoranferase; $\mathrm{Na}^{+}$: Sodium; $\mathrm{K}^{+}$: Potassium; ROS: Reactive oxygen species.

\section{Competing interests}

The authors declare that they have no competing interests.

\section{Authors' contributions}

EZ: designed the study, carried out the isolation of the strain used, challenge treatments, sample collections, performed the statistical analysis and drafted the manuscript. ER: carried out all clinical haematological analysis. All authors read and approved the final manuscript.

\section{Acknowledgements}

This study was funded by faculty of Veterinary Medicine, Mansoura University

\section{Author details}

${ }^{1}$ Department of Internal Medicine, Infectious and Fish Diseases, Faculty of Veterinary Medicine, Mansoura University, El-Gomheria Street, Mansoura, Egypt. ${ }^{2}$ Department of Clinical Pathology, Faculty of Veterinary Medicine, Mansoura University, El-Gomheria Street, Mansoura, Egypt.

Received: 21 January 2013 Accepted: 25 February 2013

Published: 9 March 2013

\section{References}

Acosta F, Ruiz de Galarreta CM, Ellis AE, Diaz R, Gómez V, Padilla D, Real F (2004) Activation of the nitric oxide response in gilthead seabream after experimental infection with Photobacterium damselae subsp. piscicida. Fish \&Shellfish Immunology 16(5):581-588. doi:10.1016/j.fsi.2003.09.010

Alvarez RM, Morales AE, Sanz A (2005) Antioxidant defenses in fish: biotic and abiotic factors. Rev Fish Biol Fisher 15:75-88

Bailey TJ (1984) Effects of twenty-five compounds on four species of aquatic fungi (Saprolegniales) pathogenic to fish. Aquaculture 38:97-104

Biswas AK, Seoka M, Tanaka YT, akii K, Kumai H (2006) Effect of photoperiod manipulation on the growth performance and stress response of juvenile red sea bream (Pagrus major). Aquaculture 258:350-356

Bly JE, Lawson LA, Dale DJ, Szalai AJ, Durborow RM, Clem LW (1992) Winter saprolegniosis in channel catfish. Dis Aquat Org 13:155-164

Bogdan C (2001) Nitric oxide and the immune response. Nature Immun 2:907-916

Bruno DW, Poppe TT (1996) A color atlas of salmonid diseases. Academic, London, England, p 189

Campos-perez JJ, Ward M, Grabowski PS, Ellis AE, Secombes CJ (2000) The gills are an important site of iNOS expression in rainbow trout Oncorhynchus mykiss after challenge with the Gram-positive pathogen Renibacterium salmoninarum. Immunology 99(1):153-161. doi:10.1046/j.13652567.2000.00914.x

Chang CF, Su MS, Chen HY, Liao IC (2003) Dietary b-1, 3-glucan effectively improves immunity and survival of Penaeus monodon challenged with white spot syndrome virus. Fish Shellfish Immunol 15:297-310

Chen SC, Yoshida T, Adams A, Thompson KD, Richards RH (1998) Non specific immune response of Nile tilapia, Oreochromis nilotica, to the extracellular products of Mycobacterium spp. and to various adjuvants. J Fish Dis 21:39-46

Copland JW, Willoughby LG (1982) The pathology of Saprolegnia infections of Anguilla anguilla L. elvers. J Fish Diseases 21:257-263, 5:421-428

Darwish AM, Mitchell AJ, Straus DL (2009) Evaluation of potassium permanganate against an experimental subacute infection of Flavobacterium columnare in channel catfish, Ictalurus punctatus (Rafinesque). J Fish Dis 32(2):193-199. doi:10.1111/j.1365-2761.2008.01015.x

Di Giulio RT, Washburn PC, Wenning RJ, Winston GW, Jewell CS (1989) Biochemical responses in aquatic animals: a review of determinants of oxidative stress. Environ Toxicol Chem 8(12):1103-1123. doi:10.1002/ etc.5620081203

Farrell AJ, Blake DR, Palmer RM, Moncada S (1992) Increased concentrations of nitrite in synovial fluid and serum samples suggest increased nitric oxide synthesis in rheumatic diseases. Ann Rheum Dis 51(11):1219-1222. doi:10.1136/ard.51.11.1219

Gallagher EP, Canada AT, Di Giulio RT (1992) The protective role of glutathione in chlorothalonil-induced stoxicity to channel catfish. Aquat Toxicol 23(3-4):155-168. doi:10.1016/0166-445x(92)90049-s

Harikrishnan R, Balasundaram C, Dharaneedharan S, Moon Y-G, Kim M-C, Kim J-S, Heo M-S (2009) Effect of plant active compounds on immune response and disease resistance in Cirrhina mrigala infected with fungal fish pathogen, Aphanomyces invadans. Aquac Res 40(10):1170-1181. doi:10.1111/j.13652109.2009.02213.x

Hussein MM, Hatai K, Nomura T (2001) Saprolegniosis in salmonids and their eggs in Japan. J Wildl Dis 37(1):204-207

Hussein MMA, Hatai K (2002) Pathogenicity of Saprolegnia species associated with outbreaks of salmonid saprolegniosis in Japan. Fish Sci 68:1067-1072

Ignarro IG (ed) (2000) Nitric oxide: biology and pathobiology. Academic, New York

Kajita Y, Sakai M, Atsuta S, Kobayashi M (1992) Immunopotentiation activity of Freund's complete adjuvant in rainbow trout Oncorhynchus mykiss [resistance to vibriosis]. Bulletin of the Japanese Society of Scientific Fisheries 58:433-437 
Kitancharoen N, Hatai K (1996) Experimental infection of Saprolegnia spp. in rainbow trout eggs. Fish Pathology 31(1):49-50

Kunttu HMT, Valtonen ET, Suomalainen L-R, Vielma J, Jokinen IE (2009) The efficacy of two immunostimulants against Flavobacterium columnare infection in juvenile rainbow trout (Oncorhynchus mykiss). Fish \& Shellfish Immunology 26(6):850-857. doi:10.1016/j.fsi.2009.03.013

Liu Y, Wang J, Wei Y, Zhang H, Xu M, Dai J (2008) Induction of time-dependent oxidative stress and related transcriptional effects of perfluorododecanoic acid in zebrafish liver. Aquat Toxicol 89(4):242-250. doi:10.1016/j. aquatox.2008.07.009

Marking LL, Rach JJ, Schreier TM (1994) American fisheries society evaluation of antifungal agents for fish culture. The Progressive Fish-Culturist 56(4):225-231. doi:10.1577/1548-8640(1994)056<0225:afseoa>2.3.co;2

Melingen GO, Stefansson SO, Berg A, Wergeland HI (1995) Changes in serum protein and IgM concentration duringsmolting and early post-smolt period in vaccinated and unvaccinated Atlantic salmon (Salmo salar L.). Fish \& Shellfish Immunology 5(3):211-221. doi:10.1016/s1050-4648(05)80015-4

Miyazaki T (1998) Influences of $\mathrm{pH}$ and temperature on Lysozyme activity in the plasma of Japanese flounder and Japanese char. Fish Pathology 33(1):7-10

Møyner K, Røed KH, Sevatdal S, Heum M (1993) Changes in non-specific immune parameters in Atlantic salmon, Salmo salar L., induced by Aeromonas salmonicida infection. Fish Shellfish Immunol 3:253-265

Noga EJ (2010) In: Noga EJ (ed) Fish disease: diagnosis and treatment / Second Edition, 2nd edn., Wiley-Blackwell, Inc., Publication

Oliveira M, Pacheco M, Santos MA (2008) Organ specific antioxidant responses in golden grey mullet (Liza aurata) following a short-term exposure to phenanthrene. Sci Total Environ 396(1):70-78. doi:10.1016/j. scitotenv.2008.02.012

Olivier G, Eaton C, Campbell N (1986a) Interaction between Aeromonas salmonicida and peritoneal macrophages of brook trout (Salvelinus fontinalis). Vet Immunol Immunopathol 12:223-234

Olivier G, Eaton C, Campbell N (1986b) Interaction between Aeromonas salmonicida and peritoneal macrophages of brook trout (Salvelinus fontinalis). Vet Immunol Immunopathol 12:223-234

Olivier G, Evelyn T, Lallier R (1985) Immunity to Aeromonas salmonicida in coho salmon (Oncorhynchus kisutch) inducfd by modified freund's complete adjuvant: Its non-specific nature and the probable role of macrophages in the phenomenon. Dev Comp Immunol 9(3):419-432

Peduzzi R, Bizzozero S (1977) Immunochemical investigation of four Saprolegnia species with parasitic activity in fish: Serological and kinetic characterization of a chymotrypsin-like activity. Microb Ecol 3(2):107-118. doi:10.1007/ bf02010400

Phillips AJ, Anderson VL, Robertson EJ, Secombes CJ, van West P (2008) New insights into animal pathogenic oomycetes. Trends Microbiol 16(1):13-19. doi:10.1016/j.tim.2007.10.013

Plumb JA, Hanson LA (2010) Principles of Health Maintenance. In: (ed) Health Maintenance and Principal Microbial Diseases of Cultured Fishes. WileyBlackwell, pp 3-30. doi:10.1002/9780470958353.ch1

Rasowo J, Okoth OE, Ngugi CC (2007) Effects of formaldehyde, sodium chloride, potassium permanganate and hydrogen peroxide on hatch rate of African catfish Clarias gariepinus eggs. Aquaculture 269(1-4):271-277. doi:10.1016/j. aquaculture.2007.04.087

Roberts RJ (2001) The mycology of Teleosts, fish pathology, 3ednth edn. W.B. Saunders, London

Robinette D, Wada S, Arroll T, Levy MG, Miller WL, Noga EJ (1998) Antimicrobial activity in the skin of the channel catfish Ictalurus punctatus: characterization of broad-spectrum histone-like antimicrobial proteins. Cell Mol Life Sci 54(5):467-475

Ruane NM, Carballo EC, Komen J (2002) Increased stocking density influences the acute physiological stress response of common carp Cyprinus carpio (L.). Aquac Res 33:777-784

Sakai M (1999) Current research status of fish Immunostimulants. Aquaculture 172:63-92

Schreier TM, Rach JJ, Howe GE (1996) Efficacy of formalin, hydrogen peroxide, and sodium. Aquaculture 140(4):323-331. doi:10.1016/0044-8486(95)01182-x

Seymour RL (1970) The genus Saprolegnia. Nova Hedwigia 19:1

Storey KB (1996) Oxidative stress: animal adaptations in nature. Braz J Med Biol Res 29:1715-1733

Straus DL, Hossain MM, Clark TG (2009) Copper sulfate toxicity to two isolates of Ichthyophthirius multifiliis relative to alkalinity. Dis Aquat Org 83:3
Stueland S, Hatai K, Skaar I (2005) Morphological and physiological characteristics of Saprolegnia spp. strains pathogenic to Atlantic salmon, Salmo salar L. J Fish Dis 28(8):445-453. doi:10.1111/j.1365-2761.2005.00635.x

Tavares-Dias M, Ruas de Moraes F, Onaka EM, Bonadio Rezende PC (2007) Changes in blood parameters of hybrid tambacu fish parasitized by Dolops carvalhoi (Crustacea, Branchiura), a fish louse. Veterinarski Arhiv 77:355-363

Thomas P, Juedes MJ (1992) Influence of lead on the glutathione status of Atlantic croaker tissues. Aquat Toxicol 23(1):11-29. doi:10.1016/0166-445x(92) 90009-c

Thomas P, Wofford HW (1984) Effects of metals and organic compounds on hepatic glutathione, cysteine, and acid-soluble thiol levels in mullet (Mugil cephalus L.). Toxicol Appl Pharm 76:172-182

Thomas-Jinu S, Goodwin AE (2004) Acute columnaris infection in channel catfish, Ictalurus punctatus (Rafinesque): efficacy of practical treatments for warmwater aquaculture ponds. J Fish Dis 27(1):23-28. doi:10.1046/j.13652761.2003.00504.x

Treves-Brown KM (2000) Applied Fish Pharmacology. Kluwer Academic Publishers, Dordrecht, pp 1-36

Tripathi NK, Latimer KS, Gregory CR, Ritchie BW, Wooley RE, Walker RL (2005) Development and evaluation of an experimental model of Cutaneous columnaris disease in Koi Cyprinus carpio. J Vet Diagn Investig 17(1):45-54. doi:10.1177/104063870501700109

Tripathi NK, Latimer KS, Lewis TL, Burnley W (2003) Biochemical reference intervals for koi (Cyprinus carpio). Comp Clin Pathol 12:160-165

Valavanidis A, Vlahogianni T, Dassenakis M, Scoullos M (2006) Molecular biomarkers of oxidative stress in aquatic organisms in relation to toxic environmental pollutants. Ecotoxicol Environ Saf 64:178-189

Van West P (2006) Saprolegnia parasitica, an oomycete pathogen with a fishy appetite: new challenges for an old problem. Mycologist 20:99-104

Vladutiu AO (1995) Role of nitric oxide in autoimmunity. Clin Immunol Immunopathol 76(1):1-11. doi:10.1006/clin.1995.1081

Whisler HC (1997) Identification of Saprolegnia Spp. Pathogenic in Chinook Salmon. U.S. Department of Energy, Bonneville Power Administration, Portland, OR, p 50pp

Wilhelm Filho D, Sell F, Ribeiro L, Ghislandi M, Carrasquedo F, Fraga CG, Wallauer JP, Simões-Lopes PC, Uhart MM (2002) Comparison between the antioxidant status of terrestrial and diving mammals. Comparative Biochemistry and Physiology - Part A: Molecular \& Integrative Physiology 133(3):885-892. doi:10.1016/s1095-6433(02)00253-2

Willoughby L (1978) Saprolegnias of salmonid fish in Windermere: a critical analysis. J Fish Dis 1:51-67

Willoughby L (1985) Rapid preliminary screening of Saprolegnia on fish. J Fish Dis 8:473-476

Yanong RP (2003) Fungal diseases of fish. Vet Clin North Am Exot Anim Pract 6 (2):377-400

Y-s K, Ke F, Zhang Q-Y (2009) Effect of b-glucan on activity of antioxidant enzymes and $M x$ gene expression in virus infected grass carp. Fish \& Shellfish Immunology 27:336-340

Zahran E, Seo J-K, Noga EJ (2012) The effect of adjuvant and microbial challenge on the expression of antimicrobial polypeptides in channel catfish (Ictalurus punctatus). Fish Shellfish Immunol (0). doi:10.1016/j.fsi.2012.03.013

Zaitseva GP, Santerre-Lucas A, Casas-Solis J, Peregrina-Sandova IJ, León-Sánchez R (2006) Tilapia Aspectos Biológicosy Productivos. Universidadde Guadalajara Coordinación Editorial, 1sted Guadalajara (Mexico)

Zhang QY, Hongmei R, Li ZQ, Gui JF (2003) Detection of grass carp hemorrhage virus (GCHV) from Vietnam and comparison with GCHV strain from China. HighTechnol Lett 9:7-13

doi:10.1186/2193-1801-2-94

Cite this article as: Zahran and Risha: Protective role of adjuvant and potassium permanganate on oxidative stress response of Nile tilapia (Oreochromis niloticus) challenged with Saprolegnia ferax. SpringerPlus 2013 2:94. 